\title{
Jeszcze o społecznych zadaniach językoznawstwa
}

\section{Further Notes on the Social Functions of Linguistics}

\author{
Bogdan Walczak \\ Wydział Humanistyczny, \\ Akademia im. Jakuba z Paradyża w Gorzowie Wielkopolskim, \\ ul. Teatralna 25, 66-400 Gorzów Wielkopolski, Polska; \\ e-mail: nataha@amu.edu.pl
}

\begin{abstract}
Abstrakt
Na wstępie autor wyjaśnia przyczyny podjęcia tytułowego zagadnienia mimo obfitości literatury naukowej na ten temat - jedna z przyczyn jest Rezolucja Europejskiej Federacji Narodowych Instytucji na rzecz Języka (EFNIL). Po przypomnieniu historycznych prolegomenów kultury języka (werdyktów normatywnych) skupia się na dwu społecznych zadaniach językoznawstwa: krzewieniu kultury i poprawności językowej oraz popularyzacji wiedzy językoznawczej. W odniesieniu do pierwszego z tych zadań rozpatruje kwestie warunków skuteczności werdyktów normatywnych oraz podstaw naukowych tych werdyktów.
\end{abstract}

Słowa kluczowe: globalizacja językowa; kultura języka; werdykt normatywny; wpływy angielskie.

\begin{abstract}
In the introductory part of this paper, the author explains the motives for undertaking the topic despite the abundance of scientific literature on the subject, one of the reasons being the Resolution of European Federation of National Institutions for Language (EFNIL). Following a review of the historical introduction to the culture of language (normative acts), the author focuses on two social functions of linguistics: propagation of culture and linguistic correctness plus dissemination of linguistic knowledge. As for the first abovementioned task, the author analyses the conditions of the effectiveness of normative acts and the scientific foundations of these acts.
\end{abstract}

Keywords: linguistic globalization; culture of language; normative act; English influences.

O społecznych zadaniach językoznawstwa (parafrazując Juliana Tuwima) można nieskończenie. $\mathrm{Z}$ wypowiedzi na ten temat uzbierałaby się już spora biblioteka ${ }^{1}$. Co zatem mnie skłania do przypomnienia tego problemu?

Po pierwsze, o pewnych ważnych społecznie sprawach trzeba przypominać nieustannie, bo wówczas pojawia się - choćby nikła - szansa, że może to odnieść jakiś skutek. Odwołam się tu do pewnej paraleli: jest francuskie przysłowie

\footnotetext{
${ }^{1}$ Sam też dołożyłem tu swoją cegiełkę: Walczak 2011b.
} 
(wiadomo, że przysłowia są mądrością narodów, a to w szczególności uchodzi za wyjątkowo zasadne, co potwierdza też współczesny polski dyskurs społeczno-polityczny): Calomniez, calomniez, il en reste toujours quelque chose, czyli: 'Oczerniajcie, oczerniajcie, zawsze coś z tego się przylepi’

Po drugie, pośrednio o społecznych zadaniach językoznawstwa przypomniał ostatnio „Poradnik Językowy”, przedrukowując w przedostatnim zeszycie Rezolucję Europejskiej Federacji Narodowych Instytucji na rzecz Języka (EFNIL) (dalej: REFNIJ), wyrażającą zaniepokojenie ,[...] rosnącą tendencją do używania języka angielskiego jako języka dydaktyki i badań naukowych" (REFNIJ 2015, 7). Dominacja angielszczyzny bądź jej wyłączność w komunikacji naukowej „[...] sprawiają, że ważne tradycje, idee i metody rozwinięte w innych językach są ignorowane lub zapominane. Ponadto główny nurt rozwoju różnych dyscyplin, decydujący o problematyce uważanej za najistotniejszą, może łatwo zostać zawłaszczony przez osoby pochodzące z krajów angielskojęzycznych, co z kolei ma wpływ na finansowanie nauki w innych krajach" (REFNIJ 2015, 7).

$\mathrm{Z}$ rezolucji pozwolę sobie tutaj przytoczyć jeszcze jeden passus:

„EFNIL, stowarzyszenie skupiające główne instytucje zajmujące się oficjalnymi językami różnych krajów europejskich, z głęboką troską obserwuje współczesną tendencję do używania języka angielskiego jako języka dydaktyki uniwersyteckiej w krajach nieangielskojęzycznych. Tendencja do stosowania angielszczyzny w miejsce języków różnych krajów w badaniach naukowych i nauczaniu akademickim zmniejsza obszary posługiwania się tymi językami, spowalnia ich rozwój i w ten sposób zagraża zróżnicowaniu językowemu Europy, tak istotnemu dla różnorodności kulturowej i bogactwa naszego kontynentu" (REFNIJ 2015, 7)

i konkluzję:

„EFNIL apeluje zatem do władz akademickich i politycznych w krajach nieanglojęzycznych, by zdecydowanie i konsekwentnie zachęcały nauczycieli i studentów do stosowania języków narodowych w badaniach naukowych i dydaktyce" (REFNIJ $2015,8)^{2}$.

Nie miejsce tu na całościową ocenę rezolucji, która miejscami trochę, jak mi się wydaje, upraszcza problem, aprobując pewne argumenty natury purystycznej ${ }^{3}$. Nie ulega jednak wątpliwości - i takie jest też stanowisko Rady Języka Polskiego przy Prezydium Polskiej Akademii Nauk (której w bieżącej kadencji mam zaszczyt być członkiem, choć mam wrażenie, że znalazłem się tam trochę jak Piłat w Credo) - że niektóre postanowienia naszych naukowych decydentów (jak na przykład wymóg tłumaczenia na angielski dokumentacji habilitacyjnej czy formułowania po angielsku wniosków grantowych - wszystko to w naukach filo-

2 Rezolucję EFNIL przedrukowały również później „LingVaria” (2015), a przedrukują pewnie i inne periodyki językoznawcze.

${ }^{3}$ Zob. w tej sprawie: Walczak 2011a. 
logicznych, w tym też w obrębie filologii narodowej ${ }^{4}$ ) świadczą nie tyle o rzeczywistej pozycji angielszczyzny jako języka międzynarodowego (narzędzia międzynarodowej wymiany myśli naukowej i technicznej), ile o fascynacji angielszczyzną, która ma wszelkie znamiona mody językowej.

W związku z tym jako historyk języka polskiego nie mogę nie przypomnieć, że już w XVI wieku o snobizmie językowym (który jest głównym źródłem mody językowej), w terminologii autora „wydwarzaniu”, pisał w 1566 roku Łukasz Górnicki: „[...] której wady pełno wszędzie, a podobno u nas w Polszcze więcej niż gdzie indziej" (cyt. za: Taszycki 1969: 63).

„Wydwarzanie”, czyli uleganie modzie językowej (tym razem czeskiej) zarzucali (już przed Górnickim, bo w pierwszej połowie XVI wieku) Janowi Sandeckiemu-Maleckiemu, gorliwemu bohemizatorowi (w dużej mierze to za jego sprawą mówimy hańba, hardy, władać (z rodziną słowotwórczą), własny, Władystaw, Wactaw itd. zamiast gańba, gardy, włodać (z rodziną), włosny, Włodzisław, Więctaw itd.), jego oponenci w pierwszej udokumentowanej filologicznie polemice poprawnościowej w Polsce - Jan Seklucjan i Stanisław Murzynowski $^{5}$. Ponieważ jednak nie operowali oni jeszcze żadnymi racjonalnymi argumentami (natury lingwistycznej czy choćby prelingwistycznej), polemiki tej nie można wpisać w nurt polskiej refleksji kulturalnojęzykowej. Ta zaczyna się od Łukasza Górnickiego, który w Dworzaninie (a w pewnej mierze też w innych publikacjach, jak w broszurze Raczyt, o której niedawno interesująco pisała Kinga Tutak (2014)) sformułował zasady racjonalnej teorii kultury języka, precyzyjnie odróżniając - w obszarze elementów obcego pochodzenia w języku polskim - to, co spowodowane wyłącznie snobizmem językowym i inercyjnym uleganiem modzie językowej, od tego, co - jak byśmy dziś powiedzieli - funkcjonalnie uzasadnione (zakorzenione w uzusie i przydatne ze względów komunikatywnych i ekspresywnych $)^{6}$. O racjonalności i zasadności teorii Górnickiego najlepiej świadczy to, że jego tezy i uzasadnienia w całości powtórzył (bez powoływania się na autora, co jednak podówczas mieściło się w standardach epoki, nie znającej naszych pojęć z zakresu własności intelektualnej) Adam Kazimierz Czartoryski (1766), a prawie w całości (dodając od siebie tylko passus o zaletach międzynarodowej (a więc nie partykularnej) terminologii naukowej i technicznej, o czym Górnicki nie wspomniał, gdyż w jego czasach, kiedy nauka była uprawiana niemal wyłącznie po łacinie, zagadnienie polskiej terminologii nie istniało jeszcze jako problem kulturalnojęzykowy) i również co już w tym wypadku musi dziwić - bez powołania się na Górnickiego Witold Doroszewski w Kryteriach poprawności językowej (1950).

${ }^{4}$ Dowcipnie i trochę złośliwie, ale w całej rozciągłości słusznie (można się bez zastrzeżeń podpisać pod każdym jego stwierdzeniem) pisze o tym w tymże zeszycie „Poradnika Językowego" Stanisław Dubisz (2015).

${ }^{5}$ Zob. na ten temat: Rospond 1938; 1939.

${ }^{6}$ O teorii Górnickiego zob.: Rzepka, Walczak 1992; Walczak 1998. 
Oczywiście, jak doskonale wiadomo - wspomnimy tutaj o tym tylko nawiasowo, by nie sugerować wniosku, że nurt polskiej refleksji kulturalno-językowej ogranicza się do idei Górnickiego - obok racjonalnej teorii starosty tykocińskiego pojawiło się stanowisko bezkrytycznych chwalców cudzoziemszczyzny (stosunkowo najgruntowniej uzasadnione w Nowych Atenach przez księdza Benedykta Chmielowskiego ${ }^{7}$ ), a później stanowisko purystyczne (stosunkowo słabo artykułowane od końca XVIII wieku ${ }^{8}$, względnie najzasadniej w wieku XIX (zob. Walczak 1999; 2010), w którym wszelako nigdy nie zyskało społecznego oparcia na miarę puryzmu czeskiego czy węgierskiego (Walczak 1987)).

Te prolegomena historyczne zakończymy przypomnieniem pozytywistycznego odróżnienia nauki czystej (jak byśmy dziś powiedzieli: badań podstawowych) i nauki stosowanej (czyli praktycznych zastosowań nauki wypływającej z motywacji czysto poznawczych). Jak wiadomo, na gruncie językoznawstwa polskiego to odróżnienie pojawiło się pod koniec XIX wieku i było w znacznej mierze związane z genezą Słownika warszawskiego (Karłowicz, Kryński, Niedźwiedzki red., 1900-1927) ${ }^{9}$. Przybrało ono, jak pamiętamy, postać paraleli: badacz języka, a z jednej strony botanik, z drugiej zaś - ogrodnik. Chodziło o to, czy badacza języka mają interesować wszystkie (bez wartościowania) fakty, zjawiska i procesy językowe - jak botanika, którego interesuje (bez wartościowania) cała flora, czy też ma fakty, zjawiska i procesy językowe wartościować - jak ogrodnik, które jedne rośliny pielęgnuje, a inne (chwasty) tępi (zob. Karłowicz 1876).

Jak powszechnie wiadomo, na gruncie polskiej lingwistyki zwyciężyła opinia o potrzebie i językoznawstwa czystego, i językoznawstwa stosowanego. Warto podkreślić, że stało się to za sprawą najniewątpliwiej najwybitniejszych ówczesnych językoznawców polskich, takich jak Jan Baudouin de Courtenay, Jan Michał Rozwadowski, Andrzej Gawroński, Jan Łoś, Kazimierz Nitsch czy Henryk Ułaszyn, którzy w tej sprawie byli absolutnie jednego zdania (zob. Nitsch 1960). Przekonanie o potrzebie językoznawstwa stosowanego (wówczas głównie, jeśli nie wyłącznie, kultury języka) zaowocowało powstaniem Towarzystwa Miłośników Języka Polskiego, które w swoim statucie za najważniejsze zadanie uznało krzewienie rozumnej miłości języka ojczystego. Trzeba tu bezwzględnie podkreślić przymiotnik rozumny, ponieważ obok rozumnej może być też i nierozumna miłość polszczyzny (bo przecież miłości do języka ojczystego nie można odmówić na przykład dość popularnemu podówczas księdzu Bolesławowi Szeffsowi (1926), który (dość rzadki u nas przykład skrajnego purysty) usiłował wyrugować z polszczyzny wszystkie wyrazy obcego pochodzenia (oczywiście arbitralnie wy-

7 Zob. Chmielowski 1745-1756 (zwłaszcza rozdział z części IV: Język polski wielu podszyty językami cudzoziemskiemi, osobliwie łacińskim, niemieckim, francuskim etc. z jakiej racyi?). Zob. też Rybicka-Nowacka, 1974.

${ }^{8}$ Zob. na ten temat: Mayenowa red., 1958-1959; Walczak 1983. W kwestii terminologii zob. ponadto: Walczak 1985.

9 O okolicznościach powstania Stownika zob. Majdak 2008. 
selekcjonowane, albowiem nie tylko on, ale i inni puryści nigdy nie byli świadomi faktu, że obcego pochodzenia są takie wyrazy jak cegła (germanizm), chata (rutenizm), duży (rutenizm) czy uprzejmy (bohemizm)).

Gdy mowa o społecznych zadaniach językoznawstwa, zazwyczaj ma się na myśli dwa:

- krzewienie kultury i poprawności językowej oraz

- popularyzację wiedzy językoznawczej.

$\mathrm{W}$ odniesieniu do pierwszego z tych zadań nasuwają się dwa podstawowe pytania:

- o skuteczność formułowanych przez językoznawców werdyktów normatywnych oraz

- o ich podstawy naukowe.

Co do pierwszego pytania: myślę, że z obszaru przeszłości i współczesności językowej można podać tyleż przykładów skuteczności werdyktów normatywnych, co i ich nieskuteczności. Tutaj musimy się oczywiście ograniczyć do wybranych pojedynczych przykładów.

Dobrego przykładu skuteczności werdyktów normatywnych dostarcza zahamowanie procesu demorfologizacji rodzaju gramatycznego w liczbie mnogiej rzeczowników. Od XVI wieku (a szczególnie w stuleciu XVII) obserwuje się w polskiej fleksji rzeczownikowej tendencję do demorfologizacji rodzaju gramatycznego (tzn. do zaniku formalnych wykładników rodzaju gramatycznego) w liczbie mnogiej. Tendencja ta doprowadziła do ustalenia się wspólnej dla wszystkich rodzajów, a więc neutralnej pod względem rodzajowym, końcówki -om w celowniku liczny mnogiej (już w XVI wieku): z dawnych końcówek -om, -em i -am pozostało jedynie -om. W XVII wieku w narzędniku liczby mnogiej $\mathrm{z}$ dawnych końcówek -y(-i), -mi i -ami pozostało - jako systemowe, kategorialne - jedynie -ami. Końcówki -mi (na przykład dłońmi, kośćmi, nićmi itd.) oraz -y(-i) (na przykład dawnymi czasy, innymi stowy, przed laty itd.) mają dziś charakter reliktowy. W tymże stuleciu w miejscowniku liczby mnogiej z -ech, -och i -ach jako systemowe, kategorialne pozostało jedynie -ach. Po -och nie ma śladu od przełomu XVI i XVII wieku, końcówka -ech (na przykład na Węgrzech, we Włoszech, $w$ Niemczech, do niedawna $w$ Prusiech itd.) ma dziś charakter reliktowy (zob. Rzepka 1985).

Ponieważ mianownik (i w liczbie mnogiej zawsze idący z nim w parze, pozbawiony własnych końcówek wołacz) oraz biernik liczby mnogiej były w dobie średniopolskiej objęte innym procesem, rozwijającym się w tym czasie: kształtowaniem się rodzaju męskoosobowego, pozostał dopełniacz. I rzeczywiście: w tendencję do demorfologizacji rodzaju gramatycznego doskonale się wpisują nieco opóźnione w stosunku do poprzednich zmiany w dopełniaczu liczby mnogiej. Wprawdzie też od XVI wieku, jednak z wyraźnym nasileniem od połowy XVIII stulecia, obserwuje się mianowicie w tym przypadku ekspansję męskiej końcówki -ów na rzeczowniki męskie miękkotematowe, żeńskie i nijakie. U najlepszych pisarzy stanisławowskich i u autorów pierwszych dziesięcioleci XIX wieku roi się 
od form typu dniów, koniów, promieniów; boginiów, komisyjów, kościów, myszów, pieśniów, trosków, wsiów, zbrodniów; bezkrólewiów, gustów, igrzysków, niebiosów, nieszczęściów, przymierzów itp. (zob. Bajerowa 1964; 1996-2000; Gajda 1973). Tendencja jest więc wyraźna: spośród trzech końcówek dopełniacza liczby mnogiej: -ów, -y(-i) i -ø zaczyna się ustalać jako jedyna, właściwa wszystkim rodzajom (a więc neutralna pod względem rodzaju gramatycznego), najbardziej z nich wyrazista (jednofunkcyjna) końcówka -ów. Proces, w świetle tego, co stało się wcześniej w celowniku, narzędniku i miejscowniku liczby mnogiej, mógł się wydawać nieodwracalny. A jednak został nie tylko zatrzymany, ale i cofnięty (jedynie część rzeczowników miękkotematowych rodzaju męskiego zachowała ekspansywną końcówkę do dziś: krajów, ojców, rodzajów itd., do początku XX wieku też kluczów, miesiąców, pisarzów itd.). Zdecydowana dezaprobata gramatyków, w szczególności cieszącego się wielkim autorytetem Onufrego Kopczyńskiego, położyła w połowie XIX stulecia kres karierze tego rodzaju, jak to żartobliwie określił Słowacki w Beniowskim, „niegramatycznościów” (Słowacki 1966: 57).

Z kolei przykładu nieskuteczności werdyktów normatywnych dostarcza szerzenie się przymiotnika unikalny mimo potępiającego werdyktu normatywistów. Piętnowali oni inkryminowany przymiotnik jako rusycyzm - co dla mnie osobiście nie stanowi rozstrzygającego argumentu ${ }^{10}$, a także, co już mnie całkowicie przekonuje, jako formację wykolejoną pod względem strukturalnym: skoro jadal$n y$ to 'taki, który nadaje się do jedzenia, którego można jeść', mieszkalny to 'taki, który nadaje się do mieszkania, w którym można mieszkać', osiagalny to 'taki, którego można osiągnąć', porównywalny to 'taki, który może być do czegoś porównany, którego można do czegoś porównać' itd. - to unikalny winien znaczyć (takie znaczenie wynika z budowy) 'taki, którego można uniknąć', a tymczasem, jak wiadomo, znaczy 'unikatowy, wyjątkowy, jedyny w swoim rodzaju'. Propozycja zastąpienia unikalnego właśnie unikatowym generalnie okazała się nieskuteczna ${ }^{11}$.

Analiza większej liczby przykładów ${ }^{12}$ prowadzi do wniosku, że skuteczność bądź nieskuteczność zależy przede wszystkim od uwarunkowań pozajęzykowych. Rozstrzygające są w tym względzie takie czynniki, jak umotywowany pozajęzykowo autorytet kodyfikatora (casus Onufrego Kopczyńskiego), rodzaj i siła motywacji użytkowników języka (motywacja ta była wyraźnie silniejsza w czasach niewoli narodowej, gdy poprawność językowa traktowana była jako sprawdzian patriotyzmu), wreszcie zintegrowany system oświatowy jako podstawowe narzędzie skutecznej polityki językowej.

${ }^{10} \mathrm{O}$ moim stanowisku wobec tzw. kryterium narodowego oceny innowacji językowych (poprawności językowej) zob. Walczak 1981; 1986; 1995.

${ }_{11}$ Więcej przykładów skutecznych i nieskutecznych werdyktów normatywnych w pracach: Walczak 2003; 2009; 2014b.

12 Zob. przypis 11. 
Co do drugiej kwestii, czyli podstaw naukowych werdyktów normatywnych, w moim przekonaniu kultura języka jako subdyscyplina lingwistyczna dopiero stosunkowo niedawno zyskała w pełni i sensu stricto naukowe, lingwistyczne podstawy dzięki strukturalistycznej koncepcji Eugenia Coseriu, który w miejsce dwuczłonowej opozycji język - tekst (langue - parole Ferdinanda de Saussure'a, kompetencja - performacja Noama Chomsky'ego) wprowadził opozycję trójczłonową: system - norma - tekst (Coseriu 1952; 1958). W koncepcji tej, jak wiadomo, między abstrakcyjnym i społecznym systemem (langue, kompetencją) a konkretnym i jednostkowym tekstem (komunikatem, wypowiedzią, przekazem, parole, performancją) sytuuje się poziom normy, rozumianej jako społecznie aprobowany zespół reguł określających zasięg dopuszczalnych realizacji systemowych modeli konstrukcyjnych w tekstach danego języka (zob. Buttler, Kurkowska, Satkiewicz 1976). Norma jest w tej koncepcji obiektywnym poziomem języka. Coseriu, a za nim adaptatorka i popularyzatorka jego koncepcji na gruncie polskim, Halina Kurkowska, przekonująco wykazali, że tekstu nie można „derywować” wprost z poziomu systemu (ściślej rzecz biorąc, w szczegółach zdarza się to dzieciom i cudzoziemcom uczącym się języka, w których tekstach pojawiają się na przykład nie tylko systemowe i zgodne z normą formy w rodzaju burzyciel, donosiciel, doręczyciel, dusiciel, krzewiciel, marzyciel, nauczyciel, odkupiciel, odnowiciel, poręczyciel, tropiciel, wielbiciel, założyciel, zbawiciel itd., ale także systemowe, lecz niezgodne z normą formy jak *bawiciel, *chwaliciel, *groziciel, *kosiciel, *kupiciel, *lowiciel, *mamiciel, *męczyciel, *prosiciel, *walczyciel, *woziciel itd., gdyż w procesie akwizycji języka system opanowuje się wcześniej niż normę). Jest to możliwe dopiero z poziomu normy, która notabene zawiera (obejmuje) także realizacje niesystemowe: relikty dawnych systemowych modeli konstrukcyjnych (jak innymi słowy, we Włoszech, dłońmi, tę itd.) i elementy dewiacyjne, wykolejone, a więc w ogóle niesystemowe, które nigdy systemowymi nie były (jak okaziciel czy truciciel) (zob. Walczak 2012; 2014a).

Werdykty normatywne formułowane ze stanowiska trójczłonowej opozycji system - norma - tekst zyskują, jak już stwierdziliśmy wyżej, solidne podstawy naukowe, co pozwala na wyeliminowanie arbitralności i subiektywizmu.

Pozostało do omówienia zadanie popularyzacji wiedzy językoznawczej. Wielokrotnie już zwracałem uwagę na wielką dysproporcję, jaka istnieje między językoznawstwem z jednej, a historią, literaturoznawstwem, kulturoznawstwem i podobnymi dyscyplinami naukowymi w zasobie wiedzy przeciętnego wykształconego Polaka (z wykształceniem wyższym lub średnim) (zob. np. Walczak 2005; 2006; 2011b; 2013). Jak się okazuje, spektakularnych (by użyć modnego i chyba nadużywanego słowa) wręcz przykładów elementarnej ignorancji w obszarze językoznawstwa dostarczają poloniści, lecz nie językoznawcy (a więc literaturoznawcy, krytycy literaccy i podobni im ludzie pióra, nawet poeci i thumacze), historycy (w tym także tacy, którzy aspirują do kompetencji w zakresie historii kultury, a więc poniekąd i historii języka polskiego jako składnika, narzędzia i tworzywa kultury), dziennikarze, regionaliści itd., nie mówiąc już o przecięt- 
nych użytkownikach polszczyzny, którzy tylko prywatnie mogą dać wyraz swojej kompletnej nieznajomości najbardziej elementarnych kwestii językowych. Rezygnując z powtarzania dowodów ignorancji lingwistycznej, mogę tutaj tylko odesłać zainteresowanych czytelników do moich wcześniejszych prac na ten temat, w szczególności do ostatnich chronologicznie artykułów jako ujmujących inkryminowany problem względnie najszerzej (Walczak 2011b; 2013).

\section{Bibliografia}

Bajerowa I., 1964, Ksztaltowanie się systemu polskiego języka literackiego w XVIII wieku, Wrocław-Warszawa-Kraków.

Bajerowa I., 1996-2000, Polski język ogólny XIX wieku. Stan i ewolucja, t. 1-3, Katowice.

Buttler D., Kurkowska H., Satkiewicz H., 1976, Kultura języka polskiego. Zagadnienia poprawności językowej, Warszawa.

Chmielowski B., 1745-1756, Nowe Ateny albo akademia wszelkiej scyjencyi petna, cz. 1-4, Lwów.

Coseriu E., 1952, Sistema, norma y habla, Montevideo.

Coseriu E., 1958, Sincronia, diacronia e historia. El problema del cambio lingüistico, Montevideo.

Czartoryski A.K., 1766, Historia nauk wyzwolonych przez P. Juvenel de Carlencas francuskim językiem pisana, na polski przełożona ad usum Korpusu Kadetów JKMci, Warszawa.

Doroszewski W., 1950, Kryteria poprawności językowej, Warszawa.

D[ubisz] S., 2015, Urzędowy bilingwizm polsko-angielski, „Poradnik Językowy”, z. 2, s. $114-115$.

Gajda S., 1973, Oboczności końcówkowe rzeczowników polskich w I połowie XIX wieku, „Rozprawy Komisji Językowej Wrocławskiego Towarzystwa Naukowego” 9, 1973, s. 93-114.

Karłowicz J., 1876, Przyczynki do projektu wielkiego słownika polskiego, „Rozprawy i Sprawozdania z Posiedzeń Wydziału Filologicznego Akademii Umiejętności” 4, s. 14-94.

Karłowicz J., Kryński A., Niedźwiedzki W. (red.), 1900-1927, Słownik języka polskiego, t. 1-8, Warszawa.

Majdak M., 2008, Stownik warszawski: koncepcja - realizacja - recepcja, Warszawa.

Mayenowa M.R. (red.), 1958-1959, Ludzie Oświecenia o języku i stylu, oprac. Z. Florczak, L. Pszczołowska, t. 1-3, Warszawa.

Nitsch K., 1960, Ze wspomnień językoznawcy, Warszawa.

REFNIJ - 2015, Rezolucja Europejskiej Federacji Narodowych Instytucji na rzecz Języka (EFNIL), „Poradnik Językowy”, z. 2, s. 7-8.

Rezolucja Europejskiej Federacji Narodowych Instytucji na rzecz Języka (EFNIL), 2015, „LingVaria” 10, nr 1, s. 7-8.

Rospond S., 1938, Kultura językowa w Polsce XVI wieku: I. Polemika poprawnościowa J. Maleckiego z J. Seklucjanem, ,Język Polski” 23, s. 45-52. 
Rospond S., 1939, Kultura językowa w Polsce XVI wieku: II. Polemika poprawnościowa J. Maleckiego z S. Murzynowskim, ,Język Polski” 24, s. 115-121.

Rybicka-Nowacka H., 1974, „,Nowe Ateny” Benedykta Chmielowskiego. Metoda, styl, ję$z y k$, Warszawa.

Rzepka W.R., 1985, Demorfologizacja rodzaju w liczbie mnogiej rzeczowników w polszczyźnie XVI-XVII wieku, Poznań.

Rzepka W.R., Walczak B., 1992, Łukasza Górnickiego teoria kultury języka, „Studia Polonistyczne" 18/19, s. 147-186.

Słowacki J., 1966, Beniowski, oprac. A. Kowalczykowa, wyd. 4. zmien., Wrocław-Warszawa-Kraków.

Szeffs B., 1926, O czystość i sprawność mowy polskiej, Pelplin.

Taszycki W., 1969, Wybór tekstów staropolskich XVI-XVIII wieku, wyd. 3., Warszawa.

Tutak K., 2014, Raczył Łukasza Górnickiego w świetle kultury języka autora Dworzanina Polskiego, „LingVaria” 9, nr 2, s. 123-136.

Walczak B., 1981, O tzw. kryterium narodowym oceny innowacji językowych, „Studia Polonistyczne" 9, s. 45-55.

Walczak B, 1983, Z problematyki językowej polskiego Oświecenia (Kampania przeciwko galicyzmom na tle ogólnojęzykoznawczych poglądów epoki), „Sprawozdania Poznańskiego Towarzystwa Przyjaciół Nauk, Wydział Filologiczno-Filozoficzny” 97-99, s. $166-176$.

Walczak B., 1985, Précis d'historie de la terminologie en Pologne, „Neoterm” 2/3, s. $15-23$.

Walczak B., 1986, O kryteriach poprawności językowej-polemicznie, „Poradnik Językowy", z. 9-10, s. 625-632.

Walczak B., 1987, Między snobizmem i modą a potrzebami języka, czyli o wyrazach obcego pochodzenia w polszczyźnie, Poznań.

Walczak B., 1995, Przegląd kryteriów poprawności językowej, „Poradnik Językowy”, z. 9-10, s. 1-16.

Walczak B., 1998, Aperçu sur la culture de la langue en Pologne, w: Europäische Sprachkultur und Sprachpflege, hrsg. A. Greule, F. Lebsanft, Tübingen, s. 153-167.

Walczak B., 1999, Zarys dziejów języka polskiego, wyd. 2., Wrocław.

Walczak B., 2003, Kultura języka z perspektywy historycznojęzykowej, „Plovdivski Universitet Paisij Chilendarski, Naučni Trudove (Filologija)" 40, kn. 1, s. 281-287.

Walczak B., 2005, W Polszcze najwięcej językoznawców, w: Region, kraj, świat. Studia ofiarowane Profesorowi Stanisławowi Tadeuszowi Olejnikowi w siedemdziesiata rocznicę urodzin, red. J.R. Budziński, Piotrków Trybunalski, s. 345-351.

Walczak B., 2006, <Staro->cerkiewno-stowiański podstawą ogólnosłowiańskiego języka literackiego?, w: W kręgu polszczyzny dawnej i współczesnej, red. E. Kołodziejek, Szczecin, s. 23-35.

Walczak B., 2009, O skuteczności ingerencji normatywnej z perspektywy historii języka, w: Polszczyzno moja ... Księga jubileuszowa z okazji 40-lecia pracy naukowej i dydaktycznej Profesora Jerzego Bralczyka, red. G. Dąbkowski, D. Lewandowska-Jaros, Warszawa, s. 299-309.

Walczak B., 2010, Cyprian Kamil Norwid o języku polskim, „Poradnik Językowy”, z. 1, s. $18-23$.

Walczak B., 2011a, Język wobec procesów globalizacji, „Annales Universitatis Paedagogicae Cracoviensis, Studia Linguistica” 6 (Dialog z tradycja, cz. 1), s. 12-20. 
Walczak B., 2011b, O społecznych zadaniach językoznawstwa polonistycznego, w: Polskie dźwięki, polskie słowa, polska gramatyka (system - teksty-norma-kodyfikacja), red. B. Pędzich, D. Zdunkiewicz-Jedynak, Warszawa, s. 33-41.

Walczak B., 2012, Aksjologia a językoznawstwo, w: Wartości i wartościowanie w badaniach nad językiem, red. M. Karwatowska, A. Siwiec, Chełm, s. 20-29.

Walczak B., 2013, Jak niespecjaliści pisza o językoznawstwie diachronicznym, „Roczniki Humanistyczne" 61, z. 6: Językoznawstwo, s. 57-75.

Walczak B., 2014a, Czy potrzebna jest obrona kultury słowa?, „Poradnik Językowy”, z. 10 , s. $90-96$.

Walczak B., 2014b, Skuteczność werdyktów normatywnych dawniej i dziś, w: Kultura mówienia dawniej i dziś, red. M. Kułakowska, A. Myszka, Rzeszów, s. 53-63. 